Dentin hassasiyet

giderici ajanların

tam seramik

restorasyonların

simantasyonuna etkisi

\section{Effect of dentin desensitizers on cementation of full ceramic restorations}

\author{
Doç. Dr. Bahadır Ersu \\ Hacettepe Üniversitesi Diş Hekimliği Fakültesi \\ Protetik Diş Tedavisi Anabilim Dalı, Ankara
}

\section{Dt. Özge Arifağaoğlu \\ Serbest Hekim}

\section{Prof. Dr. Bulem Yüzügüllü}

Başkent Üniversitesi Diş Hekimliği Fakültesi Protetik Diş Tedavisi Anabilim Dalı, Ankara

\section{Prof Dr. Şenay Canay}

Hacettepe Üniversitesi Diş Hekimliği Fakültesi

Protetik Diş Tedavisi Anabilim Dalı, Ankara

\section{ÖZET}

Amaç: Dentin hassasiyet giderici ajanlar dentin ve rezin siman arasındaki bağlantının zayıflamasına neden olabilmektedir. Bu çalışmanın amacı; gluteraldehit esaslı hassasiyet giderici ajan ve verniğin, tam seramik restorasyonlar ile dentin arasında uygulanan bir rezin simanın kesme dayanımına olumsuz etkisi olup olmadığını incelemektir.

Gereç ve Yöntem: Otuz çekilmiş insan molar dişinin okluzal yüzeyleri dentin açığa çıkana kadar aşındııımış ve dişler $(n=10)$;

1) Gluma (Heraeus Kulzer), 2) Copalite Varnish (Cooley \& Cooley Ltd) ve 3) uygulama yapılmamış (kontrol) olacak şekilde rastgele gruplandırımıştır. Seçilen ajanın uygulanmasını takiben, IPS e.max Press (Ivoclar Vivadent) diskler (5 mm çapında), Panavia $\mathrm{F}$ (Kuraray Co. Ltd) rezin siman kullanılarak $3 \mathrm{~kg}$ sabit yük altında dentin yüzeyine simante edilmiştir. Tüm örnekler Evrensel test cihazı kullanılarak kesme bağlantı dayanıklılık testine tabi tutulmuştur. Verilerin istatistiksel analizi Kruskal-Wallis ve Dunn's testi uygulanarak yapılmışı ı $(p<.05)$.

Bulgular: Kontrol grubu en yüksek ortalama kesme dayanıkllık değerlerini göstermiş olup (12.73 $\pm 3.61 \mathrm{MPa})$, Gluma $(8.73 \pm 4.95$ $\mathrm{MPa}$ ) ile kontrol grubu arasında istatistiksel olarak fark bulunmazken; Copalite Varnish $(0.88 \pm 0.25 \mathrm{MPa})$ diğer gruplara göre istatistiksel olarak daha düşük değerler göstermiştir $(p<.05)$.

Sonuç: $\mathrm{Bu}$ in vitro çalışmanın sınırları dahilinde, bağlantı dayanımını düşüreceğinden, rezin siman uygulanacağı zaman, dentin üzerinde Copalite Varnish uygulanmaması tavsiye edilebilir.

Geliş Tarihi: 25 Nisan 2016

Kabul tarihi: 13 Haziran 2016

DOI: 10.5505/yeditepe.2016.69188

Yazışma Adresi:

Prof. Dr. Bulem Yüzügüllü

Başkent Üniversitesi, Diş Hekimliği Fakültesi, Protetik Diş Tedavisi Anabilim Dalı

Eski 11.sok No:26/ 06490 Bahçelievler - Ankara

Tel: 03122151336

E-posta: bulemy@gmail.com
Anahtar kelimeler: Dentin hassasiyet giderici ajanlar, tam seramik, kesme bağlantı dayanıkııığı.

\section{SUMMARY}

Aim: Dentin desensitizers can inhibit bonding between dentin and resin cements. The aim of this study is to examine if pre-treatment with a gluteraldehyde containing desensitizer and cavity varnish have a negative effect on shear bond strength of a resin cement between a full ceramic restoration and dentin.

Material and Methods: Thirty extracted human molars' occlusal surfaces were ground to expose dentin; and were randomly 
grouped as ( $n=10) ; 1$ ) Gluma (Heraeus Kulzer), 2) Copalite Varnish (Cooley \& Cooley Ltd) and 3) no treatment (control). After applying the selected agent, Panavia F (Kuraray Co. Ltd) resin cement was used to bond IPS e.max Press (Ivoclar Vivadent) discs (5 $\mathrm{mm}$ in diameter) to dentin surfaces under a $3 \mathrm{~kg}$ static load. Specimens were submitted to shear bond strength test using a Universal testing machine. Data was statistically analyzed using the KruskalWallis and Dunn's tests $(\mathrm{p}<.05)$.

Results: While the control group showed the highest mean shear bond strength $(12.73 \pm 3.61 \mathrm{MPa})$, Gluma group values $(8.73 \pm 4.95 \mathrm{MPa})$ revealed statistically insignificant difference compared with the control group. Copalite Varnish group $(0.88 \pm 0.25 \mathrm{MPa})$ showed statistically lower values compared to both groups $(p<.05)$.

Conclusion: Within the limitation of this in vitro study, it is not recommended to use Copalite Varnish on dentin when used with resin cement due to the decrease they cause in bond strength.

Key words: Dentin desensitizing agents, full ceramic, shear bond strength

\section{GíRiş}

Son yıllarda hastaların estetik beklentilerinin artması sonucunda indirekt tam seramik restorasyon uygulamaları yaygınlaşmıştır. Bu restorasyonlar diş dokusuna adesiv resin simanlar yoluyla bağlanmaktadır. Rezin siman bağlantısı sayesinde retansiyon artmış, mikrosızıntı azalmış, dolayısıyla da postoperatif hassasiyet azalmış olur. ${ }^{2,3}$ Klinik olarak sıklıkla karşılaşılan en önemli restorasyon sonrası problemlerden birisi, indirekt adesiv restorasyonların simantasyonunu takiben ortaya çıkan aşırı hassasiyettir. ${ }^{4}$ Peparasyon sırasında büyük miktarda vital diş dokusunun uzaklaştıııması, çok sayıda dentin tübülünün açığa çıkmasına neden olmaktadır. ${ }^{5}$ Açık dentin tübülleri pulpal hasarın oluşma riskini artırmaktadır. ${ }^{6} \mathrm{Bu}$ da preparasyon sırasında uygulanan basınç veya oluşturulan ISı nedeniyle veya adesivlerin kimyasal yapısından kaynaklanabilmektedir. ${ }^{7,8}$ Brannström'ün hidrodinamik teorisine göre dentin hassasiyeti, kimyasal, termal veya osmotik uyaranlar sonucunda sıvının tübüllerden dışarı ve içeri doğru hareketi sonucu oluşmaktadır. ${ }^{9}$ Sıvı hareketi, pulpadaki sinir liflerini uyararak ağrı oluşturacak mekanik rahatsızlık yaratmaktadır.10,11

Sabit protetik restorasyonlarda post-operatif dentin hassasiyetini gidermek için günümüzde hassasiyet giderici ajanlar kullanılabilmektedir. ${ }^{12} \mathrm{Bu}$ ajanlar hassasiyeti gidermek veya azaltmak ve dentin geçirgenliğini azaltmak amacıyla dentin tübüllerini örtmek için uygulanabilmektedir. ${ }^{10}$ Dentin hassasiyetinin tedavisinde sıklıkla anti-enflamatuar ilaçlar, protein çökerticiler, tübül tıkayıcılar, vernikler ve lazer uygulamaları yer almaktadır. $^{13}$ Günümüzde kullanılan hassasiyet gidericiler florid, triklosan, benzalkonyum klorid, etilen diaminetetrasetik asit ve gluteraldehit gibi antibakteriyel komponentler içermektedir. ${ }^{14}$ Üzerinde en fazla çalışılan ajan HEMA/gluteraldehit kökenli Gluma hassasiyet gidericidir. Gluteraldehit dentin tübüllerinde protein koagülasyonu sağlamaktadır. Dentin sıvısı içindeki serum albumin ile reaksiyona girerek çökelmesine neden olmaktadır. HEMA derin rezin tagları oluşturarak dentin tübüllerini tıkamaktadır. ${ }^{15}$ Kopal vernik de hassasiyet giderici ajanlar olarak kullanılmaktadır. Hack'e ${ }^{16}$ göre verniğin yüzeyde kalmadan dentin tübüllerini tıkayabilmesi için, uygulamadan önce smear tabakasının kaldırılması gerekmektedir. Hassasiyet ajanların, dentin ile rezin siman arasındaki bağlantıya etkilerine dair literatürde farklı görüşlerde araştırmalar bulunmaktadır. Bazı araştırmacılar restorasyonun siman tasyonundan önce hassasiyet giderici ajanların uygulanmasının kron retansiyonunu azalttığı yönünde görüş bildirirken, ${ }^{2,17,18}$ diğer araştırma sonuçları olumsuz etkilerinin olmadığını, hatta artırdığını göstermektedir.10,19,20,21

$\mathrm{Bu}$ çalışmanın amacı; HEMA/gluteraldehit içerikli bir hassasiyet giderici ajan ve kavite verniğinin, tam seramik restorasyonlar ile dentin arasında uygulanan rezin simanın kesme bağlant dayanıklılığına olumsuz etkisi olup olmadığını incelemektir. 


\section{GEREÇ VE YÖNTEM}

Çalışmada 30 adet çekilmiş, çürüksüz, insan molar dişi kullanılmıştı. Dişler mekanik olarak temizlendikten sonra örneklerin hazırlanma aşamasına kadar oda sıcaklığında $\% 0,5^{\prime}$ lik kloramin içinde bekletilmiştir. Daha sonra dişlerin kökleri krondan, mine-sement sınırından yatay yönde su soğutması altında elmas diskler (Komet, Gebr Brasseler GmbH\&Co. Lemgo, Almanya) yardımıyla kesilerek ayrılmıştır. Elde edilen kron kısımları, kişisel olarak hazırlanmış Teflon kalıplara dökülen otopolimerizan akrilik rezin (Meliodent, Heraeus Kulzer, NY) içerisine, okluzal yüzleri yukarıya bakacak ve akrilik rezin kalıbın tabanına paralel olacak şekilde gömülmüştür. Standart bir yüzey elde edebilmek amacıyla, okluzal yüzeyler iri gridli elmas kesici uçlar(Komet, Gebr Brasseler GmbH\&Co. Lemgo, Almanya) kullanılarak dentin açığa çıkana kadar su altında aşındııımıştır. Bunu takiben pürüzsüz bir yüzey elde edebilmek amacıyla mekanik aşındırıcı (MetkonGrup 2V Grinder Polisher, Metkon Instruments Ldt, Bursa, Turkey) ile 600-grid silikon karbid aşındııı I kağıtlar kullanılarak yüzey düzeltilmiştir. ${ }^{2}$

Örnekler $(n=10)$ rastgele seçilerek yüzeylerine uygulanacak hassasiyet giderici ajana göre; 1) Gluma, 2) Copalite Varnish ve 3) uygulama yapılmamış (kontrol) olarak gruplandıııııştır. (Tablo 1)

\begin{tabular}{|l|l|l|}
\hline Materyaller & İcerik & Üretici Firma \\
\hline Gluma & $\begin{array}{l}\text { \%35 (2-hidroksietil) } \\
\text { metakrilat (HEMA), su, \%5 } \\
\text { gluteraldehit }\end{array}$ & Heraeus Kulzer \\
\hline Copalite Varnish & $\begin{array}{l}\text { Kopal rezin, eter, aseton, } \\
\text { alkol }\end{array}$ & Cooley\&Cooley Ltd. \\
\hline IPS e.max Press & Lityum disilikat cam seramik & Ivoclar Vivadent AG \\
\hline Panavia F2.0 simanı & $\begin{array}{l}\text { Hidrofobik aromatik dime- } \\
\text { takrilat, hidrofilik aromatik } \\
\text { dimetakrilat, MDP, sodyum } \\
\text { aromatik sülfonat, HEMA, su }\end{array}$ & Kuraray Co. Ltd. \\
\hline ED Primer (self-etching & $\begin{array}{l}\text { HEMA (2-hidroksietil } \\
\text { metakrilat), 5-NMSA } \\
\text { (N-metakriloksil-5-ami- } \\
\text { nosalisilik asit), MDP } \\
\text { (10-metakriloksidesil } \\
\text { dihidrojen fosfat), Sodyum } \\
\text { benzen sulfinat N,N'-Dieta- } \\
\text { nol-p-Toluidin,su }\end{array}$ & Kuraray Co. Ltd \\
\hline Oxyguard II & \begin{tabular}{l} 
Polietilenglikol \\
\hline
\end{tabular} & Kuraray Co. Ltd \\
\hline
\end{tabular}

Tablo 1: Çalışmada kullanılan materyaller

Seçilen hassasiyet giderici ajanlar hafifçe kurutulmuş dentin yüzeylerine üretici talimatları doğrultusunda tek kat olarak uygulandıktan sonra 60 sn beklenmiş ve yüzeyler hava ile kurutulmuştur. Uygulamalar arasında fark yaratmamak için tüm uygulamalar aynı araştırmacı tarafından yapılmıştır. Tablo 1 'de çalışmada kullanılan materyallerin özellikleri sunulmaktadır. Diş yüzeylerine simante edilmek üzere $5 \mathrm{~mm}$ çapında, $3 \mathrm{~mm}$ kalınlığında IPS e.max Press (Ivoclar Vivadent AG, Schaan, Liechtenstein) diskler seramik fırınında (Ivoclar Vivadent Pro- gramat EP 5000, Ivoclar Vivadent AG, Schaan, Liechtenstein) preslenerek hazırlanmıştır.

Simantasyondan önce birer damla A ve B primeri (ED Primer, Kuraray Co.Ltd., Osaka, Japonya) 5 sn süreyle karıştırılarak dentin yüzeylerine mikrobrush yardımıyla sürülmüştür. Primer solüsyonunun fazlalıkları pamuk peletler ile uzaklaştııılııtan sonra primer hava ile kurutulmuştur. IPS e.max Press diskler \%5 hidroflorik asit ile $20 \mathrm{sn}$ pürüzlendirildikten sonra, K Etchant Gel (Kuraray Co.Ltd., Osaka, Japonya) ile disklerin simante edilecek yüzeyleri 5 sn süreyle temizlenmiştir. Clearfil SE Bond ile Porcelain Bond Activator eşit miktarda karıştıılarak aynı yüzeylere sürülmüş ve hava ile kurutulmuştur. Panavia F 2.0 (Kuraray Co.Ltd., Osaka, Japonya) dual-polimerize rezin simanın baz ve katalizör patı eşit miktarda karıştırımış ve tam seramik diskler siman ile, $3 \mathrm{~kg}$ sabit yük altında dentin yüzeylerine simante edilmiş, taşan siman uzaklaştırımıştır. Siman, seramik disklerin yüzeyinden 20 sn süreyle ışıkla (Hilux LEDMAX-550, Benlioğlu Dental Ankara, Turkey) po limerize edildikten sonra disklerin çevresi Oxyguard Jel (Kuraray Co.Ltd., Osaka, Japonya) ile örtülmüştür. Örnekler, dayanıklılık testinden önce 24 saat süreyle $37^{\circ} \mathrm{C} \pm 2^{\circ} \mathrm{C}$ 'de distile suda bekletilmiştir.

Kesme bağlantı dayanıklıık testi, Universal test cihazı (Lloyd Instruments, Fareham, Ingiltere) kullanılarak, dentin-rezin siman arayüzeyinden kuvvet uygulanacak şekilde $1 \mathrm{~mm} /$ dak hızla gerçekleştirlmiştir. Her örnek için kesme bağlantı dayanıklığı MPa olarak, başarısızlığın gerçekleştiği en yüksek yük değerinin örneğin yüzey alanına bölünmesiyle hesaplanmıştır.

İstatistiksel analiz SPSS (Statistical Package for Social Sciences) 21 yazılımı kullanılarak yapılmıştır (SPSS Inc., Chicago, IL, ABD) Bağlanma dayanıklılık değerlerinin ortalama değerleri (MPa) ve standart sapmaları hesaplandıktan sonra, verilerin istatistiksel analizi Kruskal-Wallis ve Dunn's testi uygulanarak yapılmıştır. $P$ değerinin 0.05 'den az olması istatistiksel olarak anlamlı kabul edilmiştir.

\section{BULGULAR}

Kontrol grubu en yüksek ortalama kesme bağlantı dayanıklılık değerlerini göstermiş olup $(12.73 \pm 3.61 \mathrm{MPa})$, Gluma grubu $(8.73 \pm 4.95 \mathrm{MPa})$ ile arasında istatistiksel fark bulunmamıştır ( $p>05)$. Gerek kontrol gerek Gluma grubu ile elde edilen bağlantı dayanıklılık verileriyle karşılaştıııldığında, Copalite Varnish grubunda $(0.88 \pm 0.25$ MPa) edinilen bağlantı dayanıklılık değerleri istatistiksel olarak daha düşük bulunmuştur ( $p<.05)$ (Resim 1). 

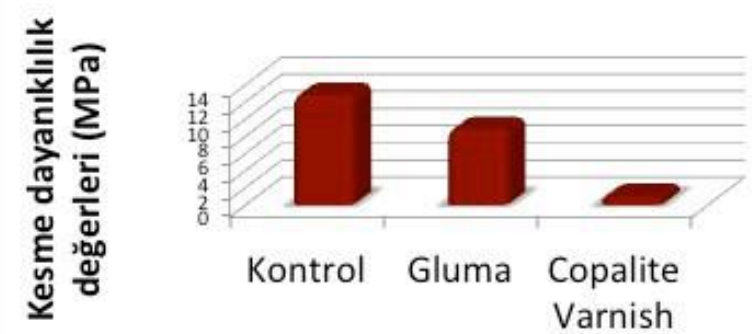

Kontrol Gluma Copalite

Varnish

\section{Hassasiyet giderici ajanlara göre gruplar}

Resim 1: Ortalama kesme bağlantı dayanıklılık değerleri (MPa)

\section{TARTIŞMA}

$\mathrm{Bu}$ in vitro çalışmada, HEMA/gluteraldehit içerikli dentin hassasiyet giderici ajan (Gluma) ve bir kavite verniği (Copalite Varnish) uygulanmış dentin yüzeyleri ile dual-cure rezin siman ile simante edilmiş tam seramik diskler arasındaki kesme bağlantı dayanıkılığı incelenmiştir. Elde edilen sonuçlar doğrultusunda Gluma, hiçbir ajan uygulanmamış örnekler ile benzer sonuçlar göstermiş, ancak Copalite Varnish ile bağlantı dayanıklılı̆ı önemli derecede azalmıştır.

Dentin dokusu ortalama 0.6-2.0 ųm çapında dentin tübülleri içermektedir. ${ }^{22} \mathrm{Her}$ cm2'de 2 milyondan fazla dentin tübülü açığa çıkmaktadır ve bir kere açığa çıktıktan sonra pulpadan ve pulpaya iletim gerçekleşmektedir. Preparasyon sırasında açığa çıkan dentin tübülleri, restorasyonun simantasyonunda kullanılan bağlantı simanı tarafından örtülmektedir. Ancak adesiv rezin siman uygulamalarında, adesiv içinde bulunan uçucu çözücüler hızla buharlaşabilmektedir ki bu da, adesiv polimerize olmadan dentin sıvısının sürekli olarak sızmasıyla sonuçlanmaktadır. $^{23}$

Dentin ile siman arasındaki bağlantı dayanıklıı̆ı üzerine literatürde bulunan araştırma sonuçlarına göre, dentin yüzeyinde Gluma uygulaması sonucunda farklı veriler elde edilmiştir. Sailer ve ark'larının ${ }^{18}$ çalışma sonuçlarına göre, self-adesiv resin siman ile birlikte uygulanan Gluma ile Panavia 21 gibi geleneksel rezin simanlara göre daha yüksek bağlantı başarısı bulunmuştur. Ancak bu çalışmada kısa süreli yaşlandırma yapıımıştır. Yim ve ark.'larının ${ }^{17}$ çalışmasının sonuçlarına göre de Gluma uygulaması sonrasında geleneksel rezin simanlarla bağlantı azalmıştır. Bunun yanı sıra, Huh ve ark.'larına ${ }^{2}$ göre de Gluma, dentin ile Panavia $F$ rezin siman arasındaki bağlantıyı olumsuz yönde etkilemiştir. Aksine, Külünk ve ark.'larıınn ${ }^{21}$ çalışmasına göre dentin yüzeyine Gluma uygulaması hiçbir ajan uygulanmamış yüzeye göre daha yüksek bağlantı dayanıklıı̆ı̆ göstermiştir. Rezin simanın bağlantı dayanıkılığının gluteraldehit yoğunluğundan çok, maksimum \%35 olan HEMA içeriğine bağlı olduğu bildirilmiştir. ${ }^{24}$ Sunulan çalışma sonuçlarına göre de Gluma uygulanan örneklerde bağlantı dayanıklılı̆ı, hassasiyet giderici ajan uygulanmayan örneklerle benzer bulunmuştur. Gözlenen bu farklı sonuçların; uygulanan farkı adesivlere, asitle pürüzlendirme yöntemlerine ve bağlantı dayanıklıık testlerinden kaynaklanabileceği düşünülebilir.

Kopal vernik 70 yıldan fazla süredir açık dentin tübüllerini kapatma yöntemi olarak kullanılmıştır. Ancak vernik uygulamalarının etkinliğinin kısa süreli olduğu bildirilmiştir. ${ }^{25}$ Günümüzde sıkça kullanılmayan verniklerin çalışmaya dahil edilme nedeni, hassasiyet gidericiler içinde bulunan re- zinin self-etching primerin etkisini engelleyerek bağlantıy azalttığı görüşünü doğrulamaktır. ${ }^{2}$ Huh ve ark.'larının² çalışma sonuçlarına benzer şekilde, sunulan çalışmada da kullanılan Copalite Varnish ED Primer ve Panavia simanın dentin ile etkileşimini engellemiş ve kesme bağlantı dayanıklılı̆ında azalmaya yol açmıştır.

Yapılan çalışmaların çoğunda bağlantı başarısının değerlendirilmesi amacıyla dentin yüzeyine yalnızca siman bloklar uygulanırken, çalışmamızda klinik ortamı daha iyi simüle edebilmek için tam seramik diskler dentin yüzeyine rezin siman vasıtasıyla simante edilmiştir. Sunulan araştırmanın sınırlamalarından birisi seramik disk/siman/dentin arayüzlerindeki bağlantı başarısızlık tiplerinin değerlendirilmemiş olmasıdır. Çalışmanın sınırlamalarından bir diğeri de sınırlı sayıda hassasiyet giderici ajan kullanılmış olmasıdır. Illaveten, çalışmada uygulanan ajanlar üretici firmaların önerileri doğrultusunda uygulanmışıı. Hassasiyet giderici ajanların kalınlıklarının da adesiv rezin simanın bağlantı dayanıklıı̆ını etkileyebileceği de düşünülmektedir. Ayrıca gelecekte yapılacak çalışmalarda farklı adeziv rezin simanların karşılaştırılması da avantaj sağlay- 
acaktır. Bunun yanı sıra, örneklere yorulma veya yaşlandırma uygulamalarının yapılması gibi farklı ortamların da değerlendirilmesinin sonuçları etkileyebileceği göz önüne alınmalıdır.

\section{SONUÇLAR}

HEMA/gluteraldehit içerikli bir hassasiyet giderici ajan ve kavite verniğinin, tam seramik restorasyonlar ile dentin arasında uygulanan rezin simanın kesme bağlantı dayanıklıı̆ına etkisini inceleyen bu in vitro çalışmanın sınırları dahilinde elde edilen sonuçlar;

1. En yüksek ortalama kesme bağlantı dayanıklılık değeri kontrol grubu ile elde edilmiş olup, Gluma uygulanan grup ile kontrol grubu arasında istatistiksel olarak fark bulunmamıştır.

2. Copalite Varnish uygulanan grupta ise ortalama kesme bağlantı dayanıklıık değerleri diğer gruplara göre istatistiksel olarak düşük bulunmuştur ( $p<.05)$.

\section{KAYNAKLAR}

1. Shafiei F, Memarpour M, Doozandeh M. Effect of oxalate desensitizer on the bonding durability of adhesive resin cements to dentin. J Prosthet Res 2012; 56: 187-193.

2. Huh JB, Kim JH, Chung MK, Lee HY, Choi YG, Shim JS. The effect of several dentin desensitizers on shear bond strength of adhesive resin luting cement using self-etching primer. J Dent 2008; 36: 1025-1032.

3. Burke FJ, Watts DC. Fracture resistance of teeth restored teeth with dentin-bonded crowns. Quintessence Int 1994; 25: 335-340.

4. Milleding P, Ortengren U, Karlsson S. Ceramic inlay systems: some clinical aspects. J Oral Rehabil 1995; 22: 571580.

5. Richardson D, Tao L, Pashley DH. Dentin permeability: effect of crown preparation. Int J Prosthodont 1991; 4: 219 225.

6. Pashley DH, Pashley EL. Dentin permeability and restorative dentistry: A status report for the American Journal of
Dentistry. Am J Dent 1991; 4: 5-9.

7. Zach L, Cohen G. Thermogenesis in operative techniques: Comparison of four methods. J Prosthet Dent 1962; 12: 977984.

8. Camps J, Pizaht S, Dejou J, Franquin JC. Effects of densitizing agents on human dentin permeability. Am J Dent 1998;

11: $286-290$.

9. Bartold PM. Dentinal hypersensitivity: A review. Aust Dent J 2006; 51:212-218.

10. Swift EJ Jr, Lloyd AH, Felton DA. The effect of resin desensitizing agents on crown retention. J Am Dent Assoc 1997; 128: $195-200$.

11. Schüpbach $P$, Lutz F, Finger WJ. Closing of dentinal tubules by Gluma desensitizer. Eur J Oral Sci 1997; 105: 414421.

12. Felton DA, Bergenholtz G, Kanoy BE. Evaluation of the desensitizing effect of Gluma Dentin Bond on teeth prepared for complete-coverage restorations. Int J Prosthodont 1991; 4: 292-298.

13. Ling TY, Gilliam DG. The effectiveness of desensitizing agents for the treatment of cervical dentine hypersensitivity (CDS)-a review. The Journal of the Western Society of Periodontology/Periodontal Abstracts 1996; 44: 5-12.

14. Malkoc S, Demir A, Sengun A, Ozer F. The effect on shear bond strength of different antimicrobial agents after acid etching. Eur J Orthod 2005; 27: 484-488.

15. Dondi dall'Orologio G, Lone A, Finger WJ. Clinical evaluation of the role of gluteraldehyde in a one-bottle adhesive. Am J Dent 2002; 15: 330-334.

16. Hack GD, Thompson VP. Occlusion of dentinal tubules with cavity varnishes. Archs Oral Biol 1994; 39: 149.

17. Yim NH, Rueggeberg FA, Caughman WF, Gardner FM, Pashley DH. Effect of dentin desensitizers and cementing agents on retention of full crowns using standardized crown preparations. J Prosthet Dent 2000; 83: 459-465.

18. Sailer I, Tettamanti S, Stawarczyk B, Fischer J, Hammerle $\mathrm{CH}$. In vitro study of the influence of dentin desensitizing and sealing on the shear bond strength of two universal resin cements. J Adhesive Dent 2010; 12: 381-392. 
19. Wolfart S, Linnermann J, Kern M. Crown retention with use of different sealing systems on prepared dentine. J Oral Rehabil 2003; 30: 1053-1061.

20. Stawarczyk B, Hartmann R, Hartmann L, Roos M, Özcan M, Sailer I, Hammerle CHF. The effect of dentin desensitizer on shear bond strength of conventional and self-adhesive resin luting cements after aging. Oper Dent 2011; 36: 492-501.

21. Külünk Ş, Saraç $D$, Külünk T, Karakaş Ö. The effects of different desensitizing agents on the shear bond strength of adhesive resin cement to dentin. J Esthet Rest Dent 2011; 23: 380-387.

22. Pashley DH. Dynamics of the pulpo-dentine complex. Critical Reviews in Oral Biology and Medicine 1996; 7: 104133.

23. Jain P, Reinhart JW, Krell KV. Effect of dentin desensitizer and dentin bonding agents on dentin permeability. Am J Dent 2000; 13: 21-27.

24. Munksgaard EC, Asmussen E. Bond strength between dentin and restorative resins mediated by mixtures of HEMA and glutaraldehyde. J Dent Res 1984; 63: 1087-1089.

25. Ferrari M, Cagidiaco MC, Kugel G, Davidson CL. Clinical evaluation of a one-bottle bonding system for desensitizing exposed roots. Am J Dent 1999; 12: 243-249. 